\title{
Real Time Traffic Density Count using Image Processing
}

\author{
Alisha Janrao \\ Department of \\ Computer Engineering \\ Smt. Kashibai Navale \\ College of Engineering \\ Divya Chandwani \\ Department of \\ Computer Engineering \\ Smt. Kashibai Navale \\ College of Engineering
}

\author{
Mudit Gupta \\ Department of \\ Computer Engineering \\ Smt. Kashibai Navale \\ College of Engineering \\ U. A. Joglekar \\ Assistant Professor \\ Department of \\ Computer Engineering \\ Smt. Kashibai Navale \\ College of Engineering
}

\begin{abstract}
Nowadays traffic jams and congestion is a common issue because of the day by day increment of numerous vehicles. A smart traffic control system can be one of the solutions to the above problem. This can be done by measuring the vehicular density on that road wherein real time image and video processing techniques will be used. The main aim is to coordinate the traffic by keeping a check of its density from all the sides and thereby controlling the traffic signal intelligently. This paper will present an algorithm so as to determine the amount of vehicles on that road. This density counting algorithm will work by the comparison between one frame of the live video (real time) and the reference image followed by looking for the vehicles in the desired region. The Otraffic signal will be controlled smartly by comparing the vehicle density and the direction of the traffic.
\end{abstract}

\section{Keywords}

Traffic Density count, Image Processing, Intelligent Controlling of Traffic, Camera, Raspberry Pi, Server.

\section{INTRODUCTION}

Following point 1.1 will give the introduction about the topic. Managing the traffic dynamically will reduce the traffic congestion. The videos are captured by stationary cameras. Then images from the live videos are retrieved one frame in a second. Image processing is performed over these retrieved frames. The output obtained from the image processing algorithm is the number of vehicles coming from a specific direction. Using this output we apply a real time traffic management algorithm which controls the traffic signal by synchronizing all the neighboring signals and manage the time duration of the signal accordingly.

\subsection{Problem Statement}

It is necessary to efficiently manage the traffic flow by completely utilizing the existing capacity of the road. Modern Cities are facing a lot of trouble due to the traffic congestion. Increasing population results in subsequent increase in the vehicles causing congestion. Traffic jams and congestion create several issues like wastage of time, excess fuel consumption. Apart from these, it directly affects routine life and sometimes may result in loss of life. E.g. In emergency cases, the ambulance boarding a critical patient cannot reach the destined hospital on time due to the congestion, where every second counts.

\section{PROJECT SCOPE}

\subsection{Aim}

To suggest a smart traffic controller system to decrease the number of traffic-jam, vacating the road which has more density of vehicles by synchronizing the traffic signals. Managing the traffic dynamically will reduce the traffic congestion

\subsection{Objectives}

The main goal is to reduce the potential jams, which are due to the traffic lights by vacating the road which has more number of vehicles, to a certain extent. Through which there will be less number of vehicles in waiting state and can reduce time consuming. And it will help clear the path for the emergency vehicles (fire brigade, ambulance, VIP person's vehicles, etc.,) if any. 


\section{LITERATURE SURVEY}

Table 1: Detail Literature Survey

\begin{tabular}{|c|c|}
\hline NAME OF THE PAPER & DESCRIPTION \\
\hline $\begin{array}{l}\text { Robust and Adaptive Traffic Surveillance System for Urban Intersections } \\
\text { on Embedded Platform }\end{array}$ & $\begin{array}{l}\text { The paper presents a real time traffic monitoring system that makes use of image processing algorithm to detect and } \\
\text { estimate the of count of vehicles using motion detection approach. }\end{array}$ \\
\hline $\begin{array}{l}\text { Real-Time Integrated CCTV Using Face and Pedestrian Detection Image } \\
\text { Processing Algorithm For Automatic Traffic Light Transitions }\end{array}$ & $\begin{array}{l}\text { Integration of face detection and pedestrian. When pedestrians are detected, it adds extra seconds to the red light and the } \\
\text { signal changes back to normal after sometime. }\end{array}$ \\
\hline $\begin{array}{l}\text { Review of the Closed Circuit Television (CCTV) Techniques for } \\
\text { Vehicular Traffic Management }\end{array}$ & $\begin{array}{l}\text { CCTV's can lessen the traffic problems.By treating video images having parameters of traffic, desired information is noted, } \\
\text { such as traffic composition, speed, shapes and types of vehicles, breaking of traffic rules or accidents. }\end{array}$ \\
\hline $\begin{array}{l}\text { An Algorithm for Full Coverage and Real Time Traffic Density } \\
\text { Calculation on Roads }\end{array}$ & $\begin{array}{l}\text { An algorithm is proposed that will increase the coverage area to the entire road. It will also assess the incoming and } \\
\text { outgoing traffic. }\end{array}$ \\
\hline $\begin{array}{l}\text { Recognition of Car Makes and Models From a Single Traffic-Camera } \\
\text { Image }\end{array}$ & $\begin{array}{l}\text { This paper reecognises car models from a single image captured by a camera. Due to various configurations of traffic } \\
\text { cameras, a traffic image may be captured in different viewpoints and lighting conditions, and the image quality varies in } \\
\text { resolution and color depth. }\end{array}$ \\
\hline $\begin{array}{l}\text { Speed Detection Camera System using Image Processing Techniques on } \\
\text { Video Streams }\end{array}$ & $\begin{array}{l}\text { A Speed Detection Camera System (SDCS) is applicable as a radar alternative. SDCS uses several image processing } \\
\text { techniques on video stream in online -captured from single camera. It uses a hybrid algorithm based on combining an } \\
\text { adaptive background subtraction technique with a three-frame differencing algorithm. }\end{array}$ \\
\hline Adaptive Traffic Control System Using Raspberry Pi & Implement an artificial density traffic control system using image processing and Raspberry Pi. \\
\hline
\end{tabular}

4. SYSTEM DESIGN

\subsection{System Architecture}

System Architecture is shown below in Figure 1

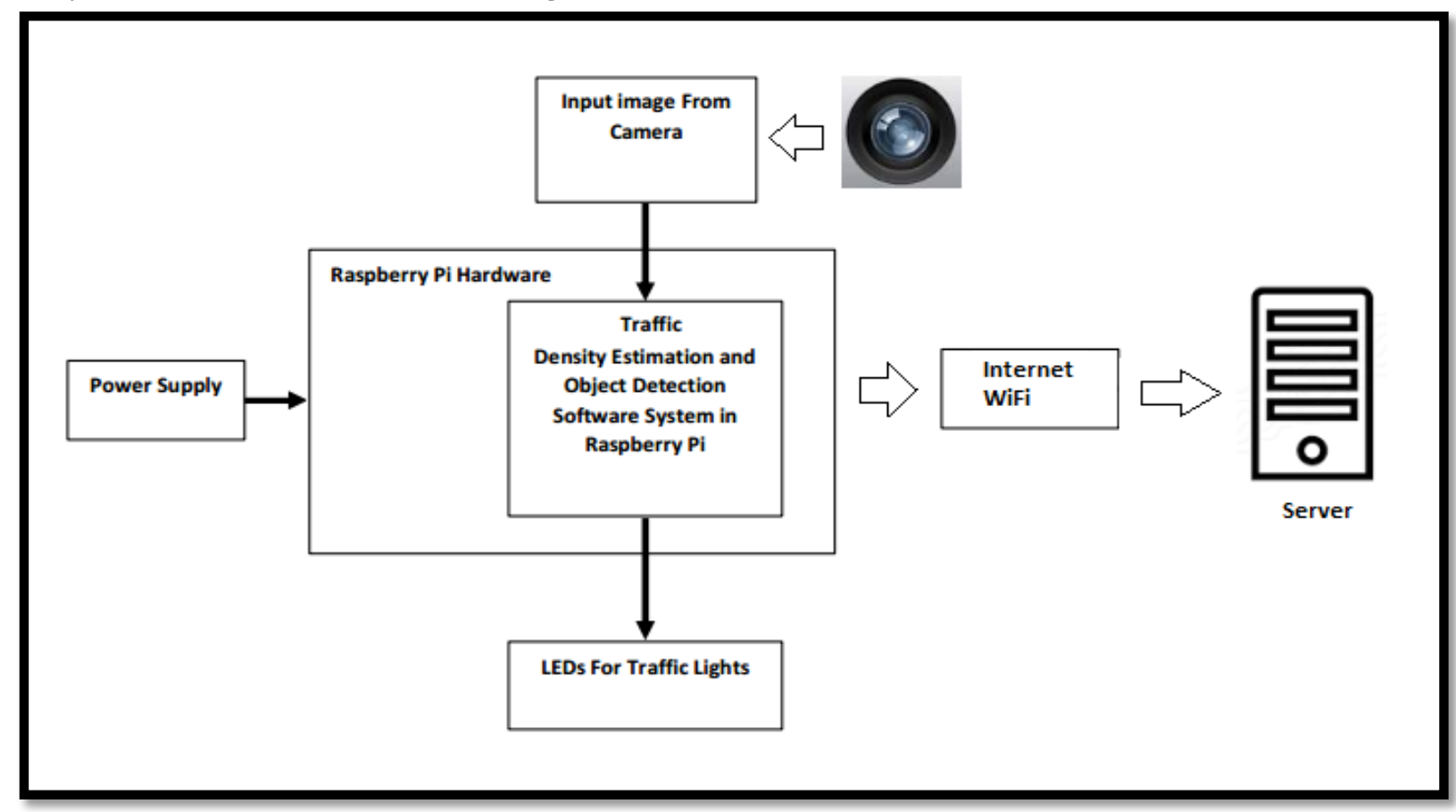

\subsection{Main modules}

\subsubsection{Camera}

The camera will be located near the traffic lights. It will capture videos of the traffic coming from a particular

direction. It will be located on an angle so that it can capture maximum number of vehicles. The camera will send the captured video to the Raspberry Pi board.

\subsubsection{Raspberry Pi Board}

Raspberry $\mathrm{Pi}$ is a credit card sized computer. It will hold the camera driver. The videos which are captured by the camera will be processed here. Images will be extracted one frame per second from the live video. An image processing algorithm will be enforced on the extracted frames. The number of objects seen in the image will be counted and it will be taken as input. A dynamic traffic management algorithm will be performed which will synchronize the traffic signals. The Raspberry Pi board will update this information on the server.

\subsubsection{Server}

The server acts as a central storage area for all the data. It collects the data generated. It will synchronize all the neighboring signals which will be helpful for later analysis 


\section{ANALYSIS MODELS}

\subsection{Data Flow diagram}

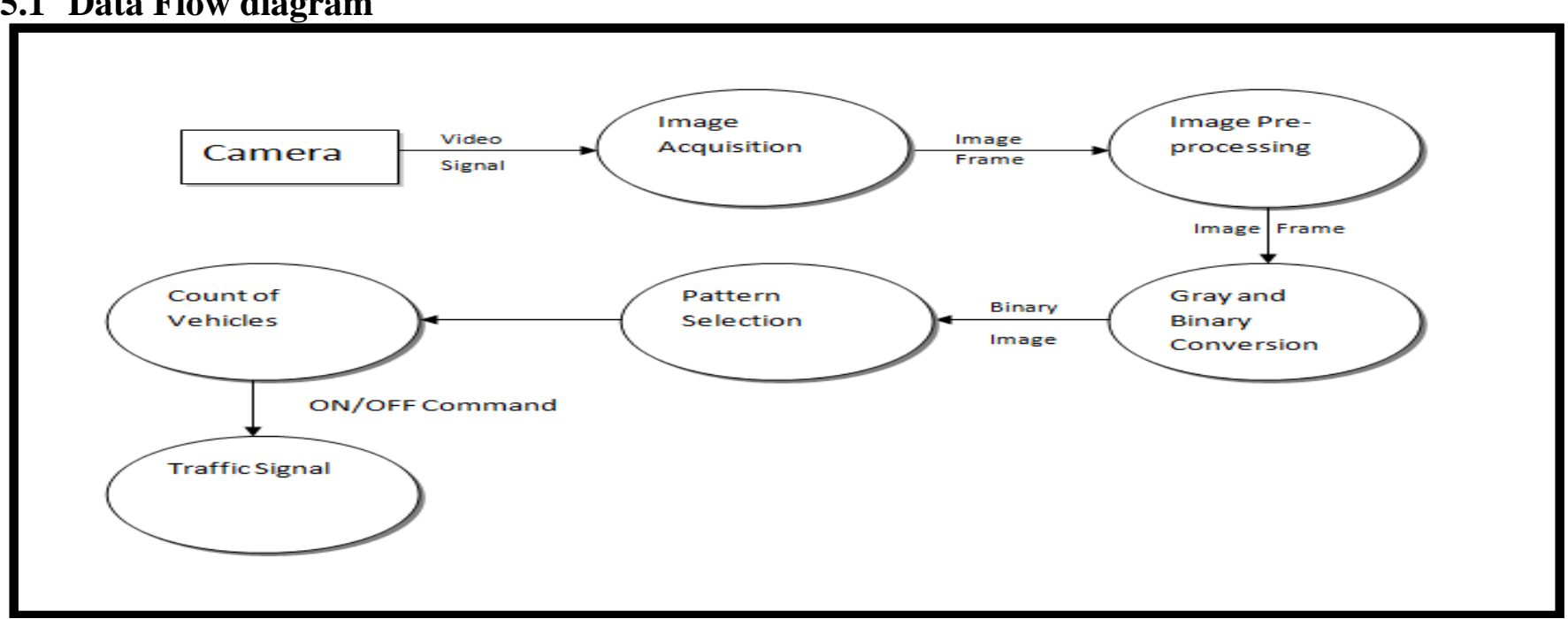

Fig 2: Data Flow Diagram.

\subsection{Sequence Diagram}

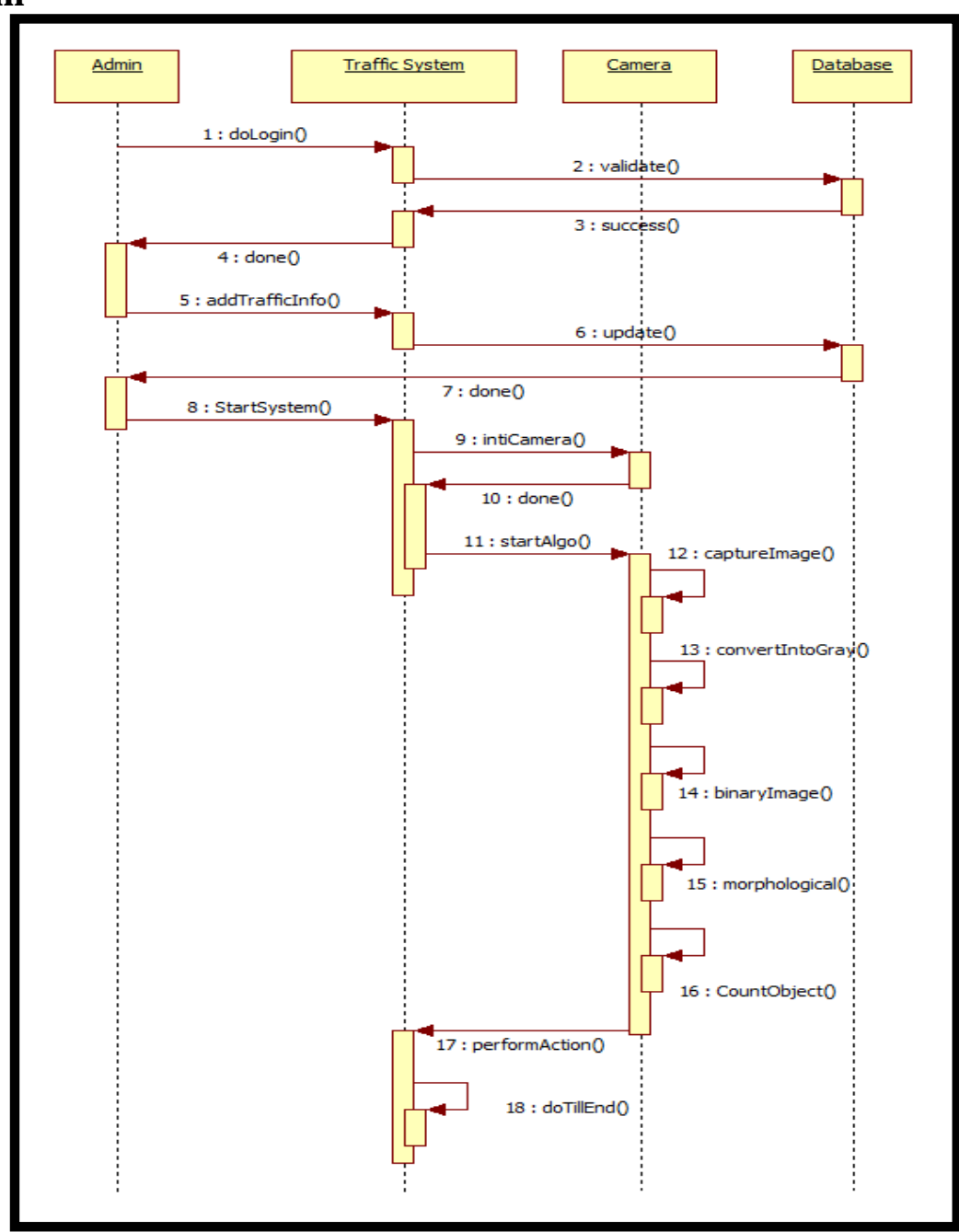

Fig 3: Sequence Diagram. 


\subsection{Use Case Diagram}

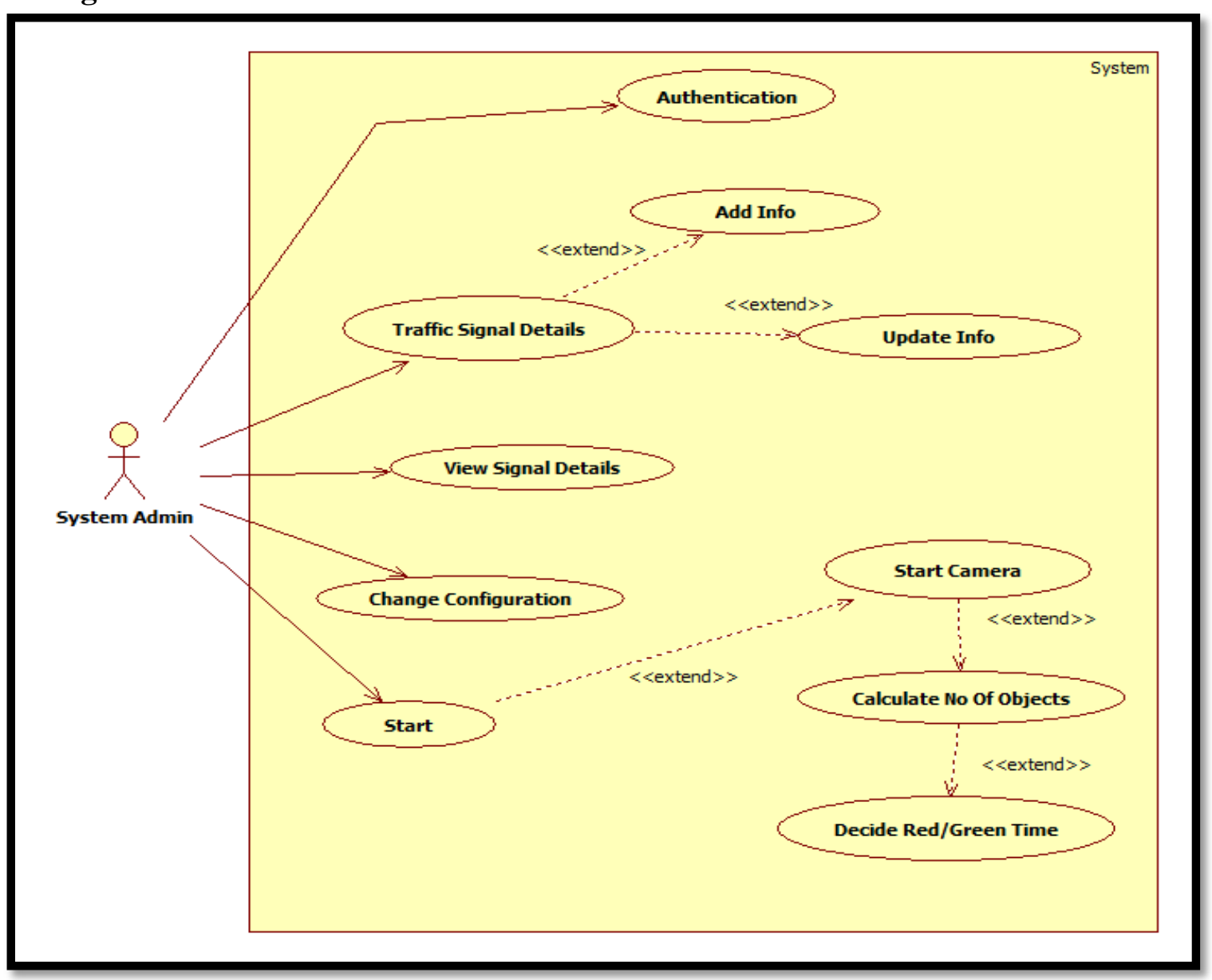

Fig 4: Use Case Diagram

\subsection{E-R Diagram}

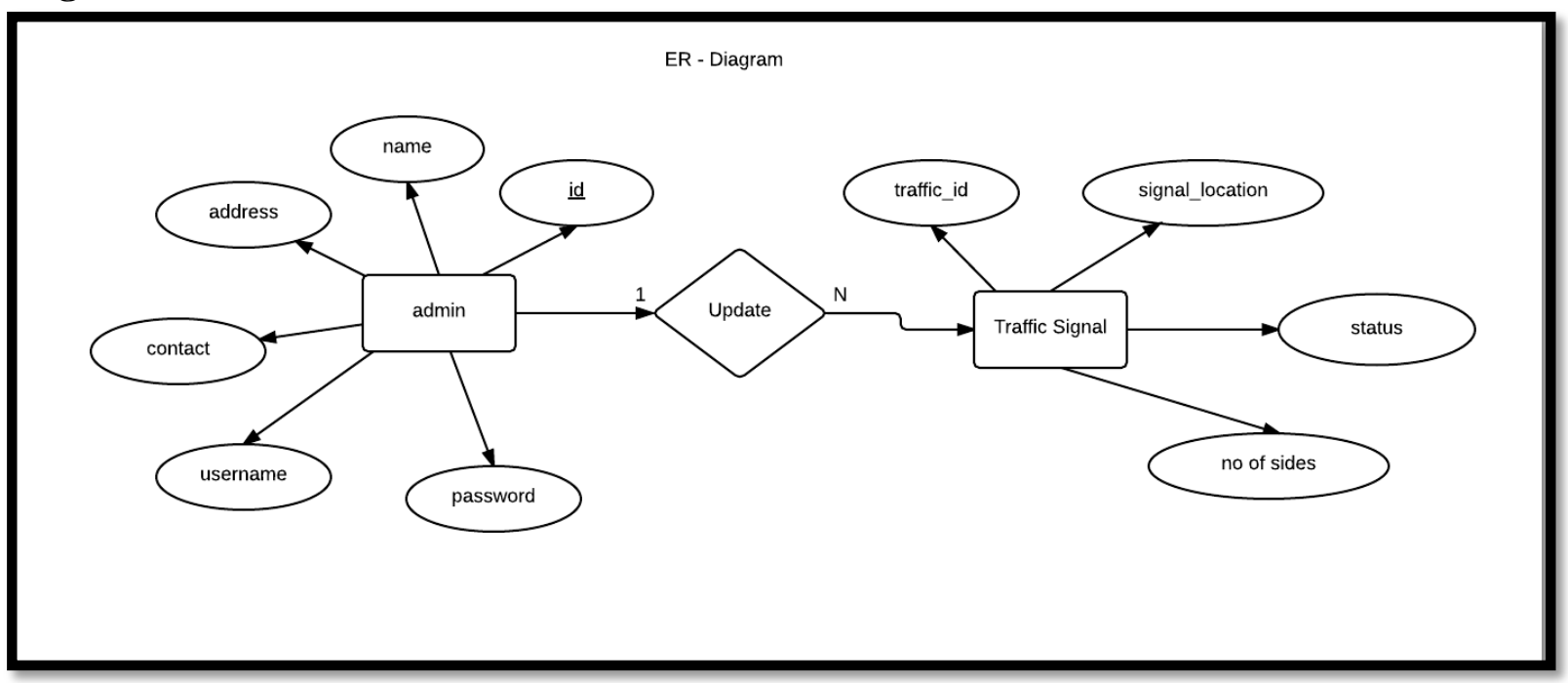

Fig 5: E-R Diagram

\section{MATHEMATICAL MODEL}

- 1. Set Theory Analysis

- 1. Let $\mathrm{S}$ be the New Traffic Light

System using Image Processing.

- $\quad$ Set $\mathrm{S}$ is divided into 6 modules

- $\mathrm{S}=\mathrm{S} 1, \mathrm{~S} 2, \mathrm{~S} 3, \mathrm{~S} 4, \mathrm{~S} 5, \mathrm{~S} 6$
- $\quad \mathrm{S} 1=\mathrm{GUI}$ Handler $(\mathrm{GH})$

- $\quad$ S2= Image Pre-processor (IP)

- $\mathrm{S} 3=$ Gray Scale Convertor (GSC)

- $\quad$ S4= Image Binarization (IB)

- $\quad$ S6= Traffic Light System (TLS) 
- $\quad$ 2. Identify the inputs.

- $\quad$ Inputs $=\mathrm{X} 1, \mathrm{X} 2, \mathrm{X} 3$

- $\mathrm{X} 1=$ Input Images

- $\mathrm{X} 2=$ Object Count

- $\quad \mathrm{X} 3=$ Image Pre-processing

- 3. Identify the output as $\mathrm{O}$.

- $\quad$ Outputs= Y1, Y2, Y3

- $\mathrm{Y} 1=$ Object Count

- $\quad \mathrm{Y} 2=$ Traffic density

- $\quad \mathrm{Y} 3=$ Traffic light On/Off

\section{CONCLUSION}

The terrific growth in the number of vehicles has led to traffic jams. The method used above of detecting the density of vehicles and processing the duration of the traffic signal, can be used for controlling the traffic, avoiding traffic congestion, accidents, etc.

Using this method at each crossway could help in a continuous journey of the people. Also, the signals will be monitored and the status of the traffic signal will be updated at the server. This will help in future reference.

Now as we are only monitoring the number of vehicles present at the signal, we can also use this method to monitor the number plate (registration no.) of the vehicle to detect the vehicles which disobey the traffic laws. We can also monitor the traffic at night since no patrol team would be required and the vehicles can run smoothly.

\section{REFERENCES}

[1] Ashwini D. Bharade, Surabhi S. Gaopande, Robust and Adaptive Traffic Surveillance System for Urban Intersections on Embedded Platform, 2014 Annual IEEE India Conference (INDICON)

[2] Cyrel O.Manlises, Jesus M. Martinez Jr. , Jackson L. Belenzo,Czarleine K. Perez,Maria Khristina Theresa A. Postrero, Real-Time Integrated CCTV Using Face and Pedestrian Detection Image Processing Algorithm For Automatic Traffic Light Transitions, 8thIEEE International Conference Humanoid, Nanotechnology, Information Technology Communication and Control, Environment and Management (HNICEM) The Institute of Electrical and Electronics Engineers Inc. (IEEE) Philippine Section

[3] Heba A. Kurdi, Review of Closed Circuit Television (CCTV) Techniques for Vehicles Traffic Management, International Journal of Computer Science \& Information Technology (IJCSIT) Vol . 6, No 2, April 2014

[4] S.Lokesh , T.Prahlad Reddy, An Adaptive Traffic Control System Using Raspberry PI, International Journal of Engineering Sciences \& Research Technology

[5] An Algorithm for Full Coverage and Real Time Traffic Density Calculation on Roads, Juma Joram Mashenene1, Xuewen Ding2, Said Kassim Katungunya3 International Journal of Science and Research (IJSR)

[6] Recognition of Car Makes and Models Froma Single Traffic-Camera Image Hongsheng He, Member, IEEE, Zhenzhou Shao, and Jindong Tan, Member, IEEE

[7] Speed Detection Camera System using Image ProcessingTechniques on Video Streams Osman Ibrahim, Hazem ElGendy, and Ahmed M. ElShafee, Member, IEEE 